\title{
Structuring meat systems using natural biopolymers
}

\author{
Boris Baranov ${ }^{1 *}$, Aleksandr Sokolov ${ }^{2}$, and Yuri Boltenko ${ }^{3}$ \\ ${ }^{1}$ Plekhanov Russian University of Economics, Moscow, Russia \\ ${ }^{2}$ Plekhanov Russian University of Economics, Moscow, Russia. Moscow State University of Food Production, Moscow, Russia \\ ${ }^{3}$ Belgorod State National Research University, Belgorod, Russia.
}

\begin{abstract}
The features of the structure and properties of raw materials, which are a source of biopolymers of natural origin are presented. The main focus of the theoretical part is paid to the study of the process of structuring of biopolymers (proteins and polysaccharides). Practical approbation was carried out on the example of meat-containing meat and meat chopped products and semi-finished products.
\end{abstract}

\section{Introduction}

Important areas of research are the stabilization of various foods environments, including the study of the properties of colloids [1-5], structuring of food systems with the disclosure of biopolymer potential (proteins, polysaccharides, etc.), technology development in various industries, including food recipes based on natural raw materials. The main tasks of work are to compare the features of structuring the biopolymers of different groups and their influence on the technological and consumer properties of culinary products on a meat basis.

\section{Experimental}

In the new laws and regulatory documents of Russia, the principle is presented - the rational use of raw materials of industries, including the food and catering industry. Therefore, the development of the theory and practice of the formation of the structure, properties of biopolymers and food, as well as the scientific substantiation of the methods of their optimal processing is the most important scientific problem.

The goal of the work is a scientific substantiation of the possibilities of using various natural sources of raw materials to obtain gelling agents (in the comparative aspect - proteins, polysaccharides) and their rational use in the technology of food and culinary products.

Waste of meat processing production were used as raw materials of animal origin - pork skins (for example, canned freezing), edge sections of the skins. The use of pork ears, beef lips, etc. is allowed.

The chemical composition of these types of raw materials is presented in Table 1 .

Analysis of data on the chemical composition of raw material sources allowed to choose raw material rich in protein biopolymers, in particular the skin of pork, ears of cattle. However, the first type of raw material is more preferable due to a more homogeneous histological structure (absence of cartilage tissue) and a greater amount of resources of its blanks, what is more practically.

Since the raw material was selected according to the criterion of biopolymers content, the next stage of the work was aimed at developing an optimal scheme for transforming the structure and disclosing the functional and technological potential of this type of protein raw material.

This method is not considered in detail, but it is necessary to note the principle of partial hydrolysis with solutions of inorganic and organic compounds (allowed to use as food additives) in a wide range of $\mathrm{pH}$ changes. This method allowed us to regulate the structure and properties in a directed manner, on the other hand, it does not require fundamental changes in the design of the equipment, it can be performed at the temperature of the workshop.

Combined hydrolysis of raw materials allowed the development of a semi-finished product, conditionally named protein structuring agent (PSA), which can be dried using a sublimation unit.

At the same time, the focus has been on structuring food systems using this semi-finished product (PSA). One of the most scientifically interesting processes is the thermotropic gelation, but its rationale requires the study of fractions of food disperse systems.

Loosening of tissue after hydrolytic effects was detected according to the light and scanning electron microscopy (SEM). In particular, there is an increase in interfiber spaces between bunches of fibers (PV) and their disorientation are noted. The hydrolytic effect led to the fact that the swelling BF and primary fibers became insufficiently distinguishable (Fig. 1). The fibrillar structures were more homogeneous. Loosening and longitudinal splitting of layers and bundles of fibers and cells due to separation of fibers or thinning of layers of loose connective tissue were revealed.

*Corresponding author: bba@bk.ru 
Table 1. Chemical composition of animal raw materials

\begin{tabular}{|c|c|c|c|c|c|c|c|}
\hline \multirow[b]{2}{*}{ Name of raw materials } & \multirow[b]{2}{*}{ Moisture } & \multirow[b]{2}{*}{ Fats } & \multicolumn{3}{|c|}{ Proteins } & \multirow[b]{2}{*}{ Ash } & \multirow[b]{2}{*}{$\begin{array}{c}\text { Water soluble } \\
\text { substances }\end{array}$} \\
\hline & & & Total & Complete & $\begin{array}{c}\text { Collagen } \\
\text { groups }\end{array}$ & & \\
\hline \multicolumn{8}{|c|}{ Pork raw } \\
\hline Pork skin (saline) & $\begin{array}{c}62.0 \pm \\
0.4\end{array}$ & $\begin{array}{c}10.1 \pm \\
0.5\end{array}$ & $\begin{array}{c}27.8 \pm \\
0.8\end{array}$ & $\begin{array}{l}1.9 \pm \\
0.6\end{array}$ & $25.9 \pm 0.6$ & $\begin{array}{c}0.60 \pm \\
0.03\end{array}$ & $\begin{array}{l}1.20 \pm \\
0.07\end{array}$ \\
\hline Skin (inter-nipple part) & 42.6 & 42.5 & 13.7 & 3.4 & 10.3 & 0.14 & 1.06 \\
\hline Skin (marginal sections) & 54.0 & 18.5 & 28.4 & - & 9.6 & 0.25 & 1.10 \\
\hline Ears & 60.9 & 14.1 & 21.0 & 8.4 & 12.6 & 0.70 & 3.30 \\
\hline \multicolumn{8}{|c|}{ Cattle raw } \\
\hline Lungs & 77.5 & 4.7 & 15.2 & 7.3 & 7.9 & 1.00 & 1.60 \\
\hline Ears & 69.8 & 2.3 & 25.2 & 10.5 & 14.7 & 0.70 & 2.00 \\
\hline Lips & 71.0 & 4.9 & 20.3 & 9.3 & 11.0 & 0.90 & 2.90 \\
\hline Rumen & 76.0 & 3.9 & 18.0 & 10.4 & 7.6 & 1.40 & 0.70 \\
\hline
\end{tabular}

The influence of the thermal process on the change in the microstructures of the PSA was studied. The features of the microstructure were established at the level of light microscopy to identify general changes in tissues and SEM - to determine the features of the architectonics of collagen fibers found throughout the entire thickness of the samples with a large depth of field.

Pores of various diameters found in almost all layers of the samples (Fig. 1), recorded in PSA samples, probably influenced by grinding, thermal gelation, etc. There are other features of the ultrastructure, but in detail in terms of technology they are not significant.

Professor G.P. Andrianova and co-authors reported that the modification changes the properties of functional groups of biopolymers, i.e. free amino, carboxyl and -OH groups appear and increase their hydration. The flooding of collagen structures was also initiated by electrostatic interaction with water dipoles, which, apparently, increased the content of tightly bound moisture and, as a result, increased the moisture binding ability. In particular, PSA exceeded the feedstock by this indicator by about $4 \%$. Apparently this is due to the activation of biopolymer centers, which increases the effect of interaction between proteins and water dipoles. A definite role here was played by the "composite" structure of raw materials - complex biopolymers of connective tissue (collagen, elastin, glycoproteins, etc.).

Based on the previously stated assumption that after heat treatment, the compound-type systems are formed that not only positively affect the functional and technological properties of minced meat products, but also contribute, a priori, to a decrease in losses of broth or nutrient solution.

Consequently, the production efficiency of meat products increases.

The molecular weight of the protein (viscometric method) in the colloidal solution was determined after a model heat treatment.

It is known that the molecular weight of tropocolagen is $300-500 \mathrm{kDa}$, and of individual polypeptide chains of collagen group proteins is from 80 to $125 \mathrm{kDa} . \alpha-, \beta$ - and $\gamma$-chains with molecular weight of 100,200 and $300 \mathrm{kDa}$ were isolated from the products of thermal denaturation of collagen. According to the data the molecular weight of dissolved protein of the PSB was approximately 200 $\mathrm{kDa}$. Therefore, it can be assumed that the presence of mainly high molecular structures similar to doublestranded $\beta$-polypeptides capable of thermotropicaly structuring the systems of the "protein protein" group, "protein-water"group, of participating in gelation.

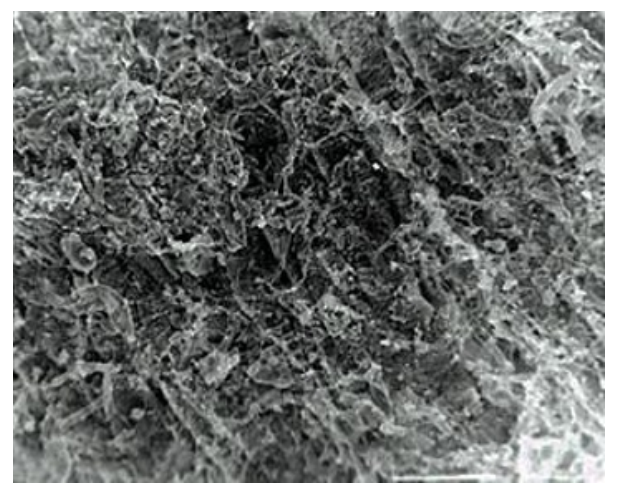

Fig. 1. Ultrastructure of the protein structuring agent $(\times 600)$.

Further research was aimed at obtaining a standard jelly based on category II by-products - sample 1 (according to the Recipe book) and model jelly (sample 2) using PSA. During the histological examination of sample 1, it was found that it is a homogeneous basophilic colored mass of biopolymers, in which particles of connective tissue are detected, which are relatively preserved by the structural organization (cell elements are not detected, the fibers are highly loosened), as well as fibers fragments, mainly elastic, turned red, fig. 2; microstructure in fig. 3 seems more homogeneous.

The summation of all data (chemical composition; sensory; histological; molecular weight) made it possible to obtain the most complete and detailed histological picture of fibrous collagen products, positive changes in its architectonics (relative homogeneity of systems, cohesion, etc.).

Jellies were prepared according to the standard recipe and experimental recipe (Table 2), according to the Recipe book.

Based on the data in Table 2, the prototype with the introduction of PSA has a slight advantage in protein content and rheological quality indicator, which confirms 
the effect of structure formation in these protein systems and improves the "tenderness" of meat-based products, which is important.

Table 2. Composition and some properties of jellies

\begin{tabular}{|c|c|c|}
\hline \multirow{2}{*}{ Indicator } & \multicolumn{2}{|c|}{ Sample } \\
\cline { 2 - 3 } & control & prototype \\
\hline Moisture, \% & 78 & 74 \\
\hline Protein, \% & 9.6 & 11.3 \\
\hline Fat, \% & 10.2 & 10.6 \\
\hline $\begin{array}{c}\text { The maximum share stress, } \\
\mathrm{kPA}\end{array}$ & 1.2 & 1.5 \\
\hline Jelly temperature, ${ }^{\circ} \mathrm{C}$ & 15.7 & 16.5 \\
\hline
\end{tabular}

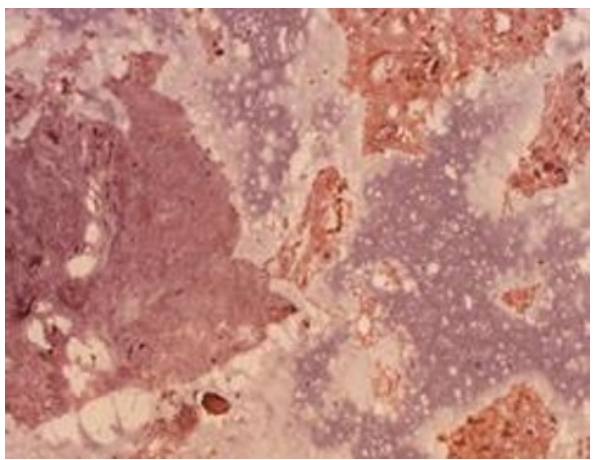

Fig. 2. Ultrastructure of the control jelly $(\times \approx 200)$.

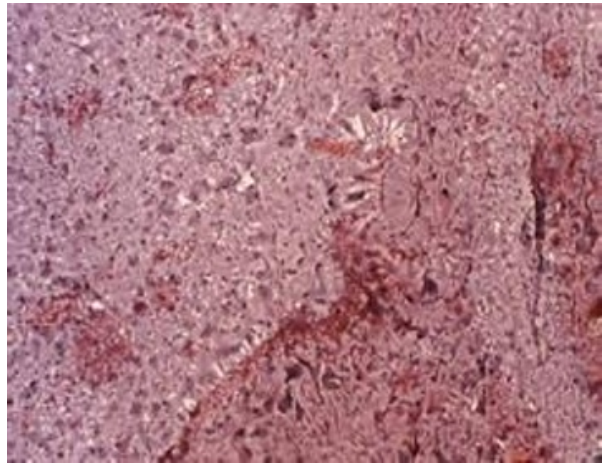

Fig. 3. Ultrastructure of a jelly with a protein structuring agent $(x \approx 200)$.

In addition, technological processes for the production of gelled products, the hydrolysis of biopolymers and, in addition, the introduction of the necessary prescription ingredients provide high organoleptic characteristics, can be «fat replacers», etc. [4].
Calculation of the energy value of the finished jelly data showed that it is for the control sample 130.2 (kcal / $100 \mathrm{~g}$ ), for prototype 140.6 (kcal / $100 \mathrm{~g}$ ), which is relatively small. In addition, we can expect the enrichment of these products with protein biopolymers, which are a source of essential substances and and dietary fiber analogues.

The next stage of the work is devoted to the study of natural biopolymers using alginates as an example in the technology of meat products and semi-finished products.

Sodium alginate is produced from natural sources; it is soluble in water. When calcium ions (gluconate, calcium lactate, etc.) are introduced into sodium alginate solutions, water-insoluble sodium-calcium polyguluronates are formed. Calcium ion connects the polysaccharide molecules with each other, their aggregation and structuring occurs. Since the interaction with calcium ions occurs quickly, calcium salts are poorly soluble in water and weakly dissociating acids are used to slow down the process, which contributes to the gradual release of calcium ions sufficient to form a gel formation. It is very important that calcium alginate forms thermostable jellies, insoluble in water, which makes it possible to use it for structuring products subjected to thermal culinary processing.

At this stage, the object of research was chopped meat and fish products. "Chopped Steak" was prepared without the addition of sowbelly to eliminate the ots unwanted influence in determining the structural and mechanical characteristics. "Natural Fish Schnitzel" was produced according to traditional technology.

As a structuring additive, we used the dry mixture developed by us, consisting of food sodium alginate, calcium carbonate and food citric acid. The amount of added mixture ranged from 0.5 to $1.5 \%$ by weight of minced meat (Table 3), which corresponds to the source [6].

Tests of chopped products were performed comprehensively by physicochemical, including rheological, and organoleptic standard methods.

Therefore, changes in indicators the moisture-holding capacity (MHC), the moisture releasing capacity (MRC), as well as water activity, have a positive effect on the value of losses during heat treatment and product yield (Table 4) and other consumer properties.

Table 3. The influence of the structuring mixture on MHC, MRC and Aw minced meat and fish

\begin{tabular}{|c|c|c|c|c|c|}
\hline \multirow{2}{*}{$\begin{array}{l}\text { The amount of the } \\
\text { added mixture, } \%\end{array}$} & \multicolumn{2}{|c|}{$\mathrm{MHC}, \%$} & \multirow{2}{*}{$\begin{array}{c}\text { MRC, } \\
\%\end{array}$} & \multirow{2}{*}{ Moisture, \% } & \multirow{2}{*}{ Water activity $\left(\mathrm{a}_{\mathrm{w}}\right)$} \\
\hline & to the mass of minced & to total moisture & & & \\
\hline \multicolumn{6}{|c|}{ Minced meat } \\
\hline 0 (control) & $57.1 \pm 0.7$ & $83.9 \pm 0.7$ & $20.8 \pm 0.4$ & $68.1 \pm 0.8$ & $0.989 \pm 0.001$ \\
\hline 0.5 & $59.7+0.7$ & $89.1+0.8$ & $15.4+0.3$ & $67.5+0.8$ & $0.988+0.002$ \\
\hline 1.0 & $62.1+0.8$ & $94.2 \pm 0.9$ & $11.6+0.3$ & $67.2 \pm 0.9$ & $0.987 \pm 0.002$ \\
\hline 1.5 & $63.0+1.4$ & $97.1+1.5$ & $9.4+0.3$ & $66.5+1.3$ & $0.986+0.003$ \\
\hline \multicolumn{6}{|c|}{ Minced fish } \\
\hline 0 (control) & $48.1 \pm 0.6$ & $60.4 \pm 0.7$ & $16.5 \pm 0.2$ & $75.7 \pm 0.9$ & $0.994 \pm 0.001$ \\
\hline 0.5 & $55.5+0.6$ & $69.3 \pm 0.7$ & $11.0 \pm 0.2$ & $75.1+0.9$ & $0.993+0.002$ \\
\hline 1.0 & $65.3+0.7$ & $83.7+0.9$ & $6.3+0.3$ & $74.6+1.1$ & $0.992+0.002$ \\
\hline 1.5 & $78.9 \pm 1.3$ & $96.6 \pm 1.2$ & $3.2 \pm 0.2$ & $73.9 \pm 1.5$ & $0.991 \pm 0.002$ \\
\hline
\end{tabular}


Table 4. The dependence of the yield of the finished product on the amount of structuring mixture

\begin{tabular}{|c|c|c|c|c|}
\hline \multirow{2}{*}{$\begin{array}{c}\text { The amount of additive, } \\
\text { in\% by the mass of } \\
\text { minced meat }\end{array}$} & "Steak" & "Schnitzel" & Mass loss with heat treatment, \% \\
\cline { 2 - 5 } & $53.0 \pm 0.5$ & $75.4 \pm 0.5$ & $29.3 \pm 0.5$ & "Schnitzel" \\
\hline 0 (control) & $57.5 \pm 0.6$ & $76.5 \pm 0.7$ & $23.4 \pm 0.6$ & $20.1 \pm 0.5$ \\
\hline 0.5 & $59.8 \pm 0.8$ & $78.8 \pm 0,8$ & $20.3 \pm 0.7$ & $18.0 \pm 0.7$ \\
\hline 1.0 & $63.2 \pm 1.0$ & $81.7 \pm 1.1$ & $15.7 \pm 1.0$ & $16.3 \pm 0.8$ \\
\hline 1.5 & &
\end{tabular}

A generalization of the research results made it possible to confirm the concept of the formation of structures based on natural biopolymers, some salts, etc., to give a fairly complete and detailed histological picture of fibrous protein systems and food products, positively assess the physicochemical changes, including architectonics (relative homogeneity of system, cohesion, etc.), therefore, the texture and other organoleptic properties of food products. The performed developments correspond to the modern level of research on biopolymers, their functional and technological features and applications $[5,6]$, including the production of meat semi-finished products and products, such as hamburgers, cutlets, etc. [7].

As a result of the research, it was found that the mass loss during the frying of the semi-finished product "Chopped Steak" and "Natural Fish Schnitzel" is reduced in proportion to the amount of additive and is reduced by almost 2 times when adding $1.5 \%$ of the test mixture.

The introduction of a structuring mixture leads to a sharp increase in the moisture-holding capacity (MHC) of minced meat (up to $97 \%$ to the total moisture) and the at the same time a decrease in the moisture releasing capacity (MRC) of minced meat by half, and fish by 2,5 times (Table 1).

\section{Conclusion}

As a result of comprehensive research, it was found that the introduction of biopolymers of various classes, including gelling mixtures, significantly increases the rheological and technological properties of meat systems, in particular, jellies, which optimizes quality. Therefore, in general, there was a tendency to increase their quality.
A comparative study of structures using alginates as an example showed the positive dynamics of moisture binding, mass loss and yield; in addition, the modulus of elasticity of the meat is increased, as well as the adhesion to stainless steel and fluoroplastic, which obviously occurs as a result of the pronounced functional and technological features of the calcium alginate gel.

For example, the stickiness of minced meat with the addition of $1.5 \%$ of the mixture is almost two times higher than that of the control sample; the maximum share stress of the finished product is reduced, i.e. products become more tender and juicy, which correlates and with organoleptic assessment.

\section{References}

1. E.I. Titov, A.Yu. Sokolov, E.V. Litvinova, S. Kidyaev, D.I. Shishkina, and B.A. Baranov, Foods and Raw Materials. 2, 7(2), 387-395 (2019)

2. A.YU. Sokolov, E.I. Titov, D.I. SHishkina, and E.V. Litvinova, Commodity expert on food products, $\mathbf{2}$, 63-66. (2019)

3. M.S. Brewer, Meat Science, 91 (4), 385-395 (2012)

4. J.-H. Choe, H.-Y. Kim, J.-M. Lee, et. al. Meat Science, 93 (4), 849-854 (2013)

5. M.C. Gomez-Guillen, B. Gimenez, M.E. LopezCaballero, and M.P. Montero, Review Food Hydrocolloids, 25 (8), 1813-1827 (2011)

6. Rodrigo Tarte, Ingredients in Meat Products. Properties, Functionality and Applications.(Professiyaб Sankt-Peterburg, 2015)

7. E.M. Desmond, D.J. Troy, and D.J. Buckley, Journal of Muscle Foods, 9 (3), 221-241 (1998) 